\title{
COMPLEX TRAINING: EFEKTIFITAS LATIHAN DALAM MENINGKATKAN POWER OTOT PADA ATLET BOLA VOLI REMAJA
}

\author{
Arif Hidayat $^{1}$, Riyan Pratama*2, M. Fransazeli Makorohim ${ }^{3}$ \\ Universitas Bina Darma, Indonesia ${ }^{1, * 2}$, Universitas Islam Riau, Indonesia ${ }^{3}$ \\ Email: arif.hidayat@binadarma.ac.id ${ }^{1}$,riyan_pratama@binadarma.ac.id ${ }^{* 2}$, \\ mfransazeli@edu.uir.ac.id ${ }^{3}$
}

Received: 09 Mei 2020; Accepted 02 October 2020; Published 24 November 2020 Ed 2020; 5(2): 146-154

\begin{abstract}
ABSTRAK
Complex training merupakan sebuah metode latihan yang menggabungkan plyometrics dengan latihan kekuatan. Latihan ini merupakan latihan yang digunakan untuk meningkatkan daya ledak otot (power). Penelitian ini bertujuan untuk mengetahui pengaruh latihan metode complex training terhadap power otot tungkai dan power otot lengan bagi atlet bola voli remaja. Metode yang digunakan dalam penelitian ini adalah eksperimen dengan desain control groups pretest-posttest design. Subjek dalam penelitian ini adalah 23 atlet remaja bola voli (14-17 tahun) dengan 12 orang putera dan 11 orang puteri, yang dibagi menjadi dua kelompok kelompok eksperimen $(\mathrm{n}=12)$ dan kelompok kontrol $(\mathrm{n}=11)$ dengan randomized matched pair design berdasarkan peringkat dari kemampuan vertical jump. Instrumen yang digunakan vertical jump test (otot tungkai) dan medicine ball throw test (otot lengan). Teknik analisis data yang digunakan adalah uji paired t test dengan taraf signifikasi $\alpha=0,05$. Hasil penelitian menunjukan bahwa latihan menggukan metode complex training memberikan manfaat yang baik dalam meningkatkan power otot tungkai dan lengan. Oleh karena itu, metode ini sangat cocok untuk digunakan bagi atlet bola voli tingkat remaja yang telah memiliki pengalaman latihan beban dalam meningkatkan power otot bagi atlet bola voli tingkat remaja.
\end{abstract}

Kata Kunci: Complex Training; Power; Otot Tungkai; Otot Lengan

\section{COMPLEX TRAINING METHOD: EFFECTIVENESS OF TRAINING IN IMPROVING MUSCLE POWER ON ADOLESCENT VOLLEYBALL ATHLETES}

\begin{abstract}
Complex training is an exercise method that combines plyometrics with strength training. This exercise is an exercise used to increase muscle power. This study aims to determine the effect of training of complex training methods towards leg muscle power and arm muscle power for adolescent volleyball athletes. The method used in this study is an experiment with a control group pretest - post test design. Subjects in this study are 23 adolescent volleyball athletes (14-17 years old) with 12 males and 11 females, who are divided into two groups of experimental groups $(n=12)$ and control groups $(n=11)$ with randomized matched pair design based on the ranking of the vertical jump ability. Instrument used in this study is vertical jump test (leg power) and the medicine ball throw test (arm power). The data analysis technique uses the paired t-test with a significance level of $\alpha=0.05$. The results show that training using a complex training method provides a good benefit in improving leg and arm muscle power. Therefore, this method is appropriate for used by adolescent volleyball athletes that have had experience of weight training in improving muscle power towards adolescent volleyball athletes.
\end{abstract}

Keyword: Complex Training; Power; Legs Muscle; Arm Muscle

Copyright (C) 2020, Journal Sport Area

DOI: https://doi.org/10.25299/sportarea.2020.vol5(2).5012

How To Cite: Hidayat, A., Pratama, R., \& Makorohim, M. F. (2020). Complex Training: Efektifitas Latihan Dalam Meningkatkan Power Otot Pada Atlet Bola Voli Remaja. Journal Sport Area, 5(2), 146154. 


\section{PENDAHULUAN}

Tujuan dari latihan adalah untuk meningkatkan kinerja. Dalam olahraga kinerja tersebut menyangkut kondisi fisik maupun teknik. Dengan berlatih dapat meningkatkan potensi yang dimiliki. Latihan beban meurupakan salah satu cara yang dapat ditempuh untuk mengasah potesi, khususnya untuk atlet dalam cabang olahraga. Mansur, Irianto, dan Mansur (2018) menyatakan bahwa untuk mencapai prestasi tinggi dalam olahraga kompetitf, diperlukan kondisi fisik yang prima sesuai dengan kebutuhan cabang olahraga. Bola voli merupakan olahraga yang eksplosif, hal ini berarti bola voli memerlukan latihan yang bersifat power. Reynaud (2011) menyatakan bahwa bola voli merupakan cabang olahraga yang mengutamakan power. Dalam permainan bola voli, power terlibat dalam hampir semua teknik dalam permainan ini, baik dalam situasi menyerang maupun bertahan.

Agar dapat melakukan gerakan-gerakan yang eksplosif maka diperlukan kekuatan sebagai fondasi. Oleh karena itu kekuatan merupakan bagian integral dari kinerja dalam cabang olahraga. Power otot dianggap sebagai komponen dasar dari kinerja fisik dan faktor-faktor yang mempengaruhi adalah kekuatan. Berdasarkan survei yang dilakukan oleh peneliti di lapangan, dalam latihan yang selama ini dilakukan oleh pelatih di Sekolah Olahraga Negeri Sriwijaya khususnya cabang olahraga bola voli. Untuk meningkatkan power, baik tungkai maupun lengan, pelatih memberikan latihan yang terpisah antara latihan beban dan plyometrics. Dalam latihan beban pelatih biasanya menggunakan metode set block atau pyramid. Hal ini dinilai kurang efisien dalam hal waktu. Oleh karena itu peneliti menawarkan alternative latihan untuk meningkatkan power otot yaitu complex training. Macaluso (2010) mengukapkan bahwa complex training merupakan cara yang aman dan efektif untuk atlet dengan tujuan meningkatkan power otot.

Complex training merupakan metode latihan yang menggabungkan satu set latihan kekuatan dengan dengan serangkaian latihan plyometrics yang sebanding dalam sesi latihan yang sama dan diyakini dapat meningkatkan kualitas dari stimulus latihan plyometrics (Ali, Verma, Ahmad, Singla, \& Jha, 2017). Metode latihan ini merupakan metode latihan dinamis dengan intensitas tinggi (Lim \& Barley, 2016). Teknik latihan ini mengambil keuntungan dari post activation potensiasi (PAP) yang didefinisikan sebagai sebuah fenomena otot yang menyebabkan peningkatan daya otot secara akut (Lorenz, 2011). Peningkatan kinerja otot ini disebabkan oleh otot dalam keadaan potensial atau aktif.

Dalam metode complex training faktor krusial yang menentukan efisiensi dan hasil latihan adalah faktor intesitas latihan berdasarkan tes awal latihan (Ali et al., 2017). Untuk penentuan intensitas latihan beberapa peneliti menyampaikan intensitas yang berbeda-beda. Latihan beban dapat menjadi kegiatan yang aman, efektif dan bermanfaat bagi anak-anak dan remaja asalkan memenuhi syarat profesional mengawasi semua sesi pelatihan dan memberikan instruksi yang sesuai dengan usia dan teknik yang benar sebagai prosedur dan pedoman latihan yang aman (Faigenbaum \& Myer, 2010). Mohamed (2011) menyatakan bahwa penggunakan beban dengan intensitas atara 50\%$60 \%$ berefek peningkatan kinerja pada atlet senam muda. Pertimbangan selanjutnya adalah istirahat guna mempertahankan kinerja tetap optimal.

Istirahat merupakan salah satu kunci dalam latihan. Karena istirahat dapat mempengaruhi efek akut maupun kronis dari suatu latihan. Dengan kata lain, istirahat menentukan maksud dan tujuan dari suatu latihan. Seperti apabila tujuan dari latihan adalah untuk hipertrofi otot (8-12 RM) direkomendasikan waktu interval (istirahat) 30- 
60 detik, pemilihan watu istirahat tersebut dikarenakan pada rentang waktu tersebut memiliki efek akut paling efektif pada hormon pertumbuhan yang merangsang pertumbuhan otot (De Salles, Simão, Miranda, Novales, Lemos, \& Willardson, 2009). Untuk latihan menggunakan metode complex training terdapat Intra Complex Rest Interval (ICRI). ICRI merupakan waktu antara latihan beban dan pliometrik. Menurut Carter dan Greenwood (2014) bahwa ICRI yang optimal adalah minimal 2 menit. Rekomendasi waktu yang digunakan untuk ICRI adalah 3-4 menit (Lim \& Barley, 2016). Dengan demikian pengaturan istirahat dalam latihan complex training sangat dibutuhkan untuk mendapatkan hasil yang optimal.

Berdasarkan aturan dari complex training yang menggabungkan latihan beban dan pliometrik dalam satu sesi yang sama yang bertujuan untuk meningkatkan power pada otot seorang atlet (May, Cipriani, \& Lorenz, 2010). Berdasarkan hal tersebut maka penting untuk diuji sejauh mana efek dari latihan complex training ini dalam meningkatkan power atlet remaja bola voli. Berdasarkan hal tersebut tujuan dari penelitian ini adalah untuk mengetahui efek dari complex training pada power otot tungkai dan lengan bola voli remaja.

\section{METODE PENELITIAN}

Metode yang digunakan dalam penelitian ini adalah eksperimen dengan desain control groups pretest-posttest design. Dua kelompok dalam penelitian ini, Kelompok eksperimen (EG) dan kelompok kontrol (CG). Kelompok eksperimen (EG) melakukan latihan beban dengan metode complex training dengan frekuensi 2 kali dalam satu minggu dan tetap berlatih bola voli secara reguler. Kelompok kontrol (CG) tidak melakukan latihan beban dan tetap berlatih bola voli secara reguler.

Subjek dalam penelitian ini adalah 23 atlet muda bola voli (14-17 tahun) yang berisi 12 orang putra dan 11 orang putri, yang dibagi menjadi dua kelompok EG $(n=12)$ dan CG $(\mathrm{n}=11)$ dengan randomized matched pair design berdasarkan peringkat dari kemampuan vertical jump. Semua subjek penelitian telah memiliki pengalaman berlatih minimal 2 tahun.

Sebelum dan sesudah perlakuan latihan selama 12 minggu menggunakan latihan complex training, subjek penelitian diukur power otot bagian atas dan bagian bawah. Instrumen pengukuran yang digunakan untuk mengukur tersebut adalah medicine ball throw dan vertical jump test (Fukuda, 2019). Sebelum melakukan tes ini atlet muda bola voli diharuskan untuk melakukan pemanasan terlebih dahulu untuk mendapatkan hasil tes yang sesungguhnya. atlet diberikan masing-masing dua kali kesempatan untuk melakukan kedua tes ini. Latihan dilakukan selama 12 minggu, dengan frekuensi 2 kali 1 minggu. Adapun program latihan yang dilakukan dalam penelitian ini sebagai berikut:

Tabel 1. Latihan Minggu 1-3

\begin{tabular}{lllll}
\hline \multicolumn{4}{l}{ Resistance Training } & \multicolumn{2}{l}{ Plyometric Training } & \\
\hline Upper Body & Chest Press & $2 \times 10 / 12 \mathrm{RM}$ & Med Ball Slam & $2 \times 8$ repetisi \\
& Pull Down & $2 \times 10 / 12 \mathrm{RM}$ & $\begin{array}{l}\text { Med Ball Slam Side } \\
\text { Throw }\end{array}$ & $2 \times 8$ repetisi \\
& & & Throw & \\
Lower Body & Shoulder Press & $2 \times 10 / 12 \mathrm{RM}$ & Med Ball Wall Ball & $2 \times 8$ repetisi \\
& Lungges & $2 \times 10 / 12 \mathrm{RM}$ & Sprint 20 M & $2 \times 4$ repetisi \\
& Calf Rise & $2 \times 10 / 12 \mathrm{RM}$ & Double Leg Hops & $2 \times 8$ repetisi \\
& Deadlift & $2 \times 10 / 12 \mathrm{RM}$ & Tuck Jump & $2 \times 8$ repetisi \\
\hline
\end{tabular}


Arif Hidayat, Riyan Pratama dan M. Fransazeli Makorohim (2020)

Complex Training: Efektifitas Latihan Dalam Meningkatkan Power Otot Pada Atlet Bola Voli Remaja

Tabel 2. Latihan Minggu 4-7

\begin{tabular}{lllll}
\hline \multicolumn{4}{l}{ Resistance Training } & Plyometric Training \\
\hline Upper Body & Chest Press & $3 \times 10 / 12 \mathrm{RM}$ & Medball Rainbow Slam & $2 \times 8$ repetisi \\
& Pull Down & $3 \times 10 / 12 \mathrm{RM}$ & Medball Side Throw & $2 \times 8$ repetisi \\
& Shoulder Press & $3 \times 10 / 12 \mathrm{RM}$ & Medball V Swing & $2 \times 8$ repetisi \\
& Lungges & $3 \times 10 / 12 \mathrm{RM}$ & Sprint 20 M & $2 \times 4$ repetisi \\
Lower Body & Calf Rise & $3 \times 10 / 12 \mathrm{RM}$ & Kneeling Verticall Jump & $2 \times 8$ repetisi \\
& Deadlift & $3 \times 10 / 12 \mathrm{RM}$ & Explosive Step Up & $2 \times 8$ repetisi
\end{tabular}

Tabel 3. Latihan Minggu 8-12

\begin{tabular}{lllll}
\hline \multicolumn{4}{l}{ Resistance Training } & \multicolumn{2}{l}{ Plyometric Training } \\
\hline & Chest Press & $4 \times 10 / 12 \mathrm{RM}$ & Medball Slam & 2x8 repetisi \\
& Pull Down & $4 \times 10 / 12 \mathrm{RM}$ & Medball Rainbow Slam & $2 \times 8$ repetisi \\
Upper Body & Shoulder Press & $4 \times 10 / 12 \mathrm{RM}$ & Medball Back Toss & $2 \times 8$ repetisi \\
Lower Body & Lungges & $4 \times 10 / 12 \mathrm{RM}$ & Sprint 20 M & $2 \times 6$ repetisi \\
& Calf Rise & $4 \times 10 / 12 \mathrm{RM}$ & Box Jump & $2 \times 8$ repetisi \\
& Deadlift & $4 \times 10 / 12 \mathrm{RM}$ & Depth Jump & $2 \times 8$ repetisi \\
\hline
\end{tabular}

Analisis data yang dikumpulkan menggunakan uji t untuk mengalisis perbedaan antara kelompok eksperimen (EG) dan kelompok kontrol (CG) dengan taraf signifikansi 0,05 .

\section{HASIL DAN PEMBAHASAN}

Hasil yang diperoleh dari penelitian berupa daya yang merupakan gambaran umum tentang masing-masing variabel yang terkait dalam penelitian. Berikut hasil dari pretest dan posttest power tungkai dan power lengan atlet bola voli remaja.

Tabel 4. Deskripsi Statistik

\begin{tabular}{|c|c|c|c|c|}
\hline \multicolumn{5}{|c|}{ Power Tungkai } \\
\hline & \multicolumn{2}{|c|}{ Kel. Eksperimen } & \multicolumn{2}{|c|}{ Kel. Kontrol } \\
\hline & Pretest & Posttest & Pretest & Posttest \\
\hline $\mathrm{N}$ & 11 & 11 & 11 & 11 \\
\hline Mean & 50,36 & 70,00 & 49,36 & 50,45 \\
\hline $\mathrm{SD}$ & 11,63 & 13,84 & 12,07 & 10,83 \\
\hline Min & 39,00 & 52,00 & 31,00 & 35,00 \\
\hline Max & 68,00 & 95,00 & 67,00 & 67,00 \\
\hline \multicolumn{5}{|c|}{ Power Lengan } \\
\hline & \multicolumn{2}{|c|}{ Kel. Eksperimen } & \multicolumn{2}{|c|}{ Kel. Kontrol } \\
\hline & Pretest & Posttest & Pretest & Posttest \\
\hline $\mathrm{N}$ & 11 & 11 & 11 & 11 \\
\hline Mean & 4,37 & 5,06 & 4,06 & 4,24 \\
\hline SD & 0,89 & 0,61 & 0,68 & 0,52 \\
\hline Min & 3,15 & 4,25 & 3,21 & 3,40 \\
\hline Max & 5,47 & 5,81 & 5,18 & 5,16 \\
\hline
\end{tabular}


Tabel 5. Uji Normalitas

\begin{tabular}{cccc}
\hline \multicolumn{5}{c}{ Kelompok Eksperimen } & \\
\hline & $\mathbf{p}$ & Sig. & Keterangan \\
\hline Pretest Power Tungkai & 0,12 & 0,05 & Normal \\
Posttest Power Tungkai & 0,20 & 0,05 & Normal \\
Pretest Power Lengan & 0,20 & 0,05 & Normal \\
Posttest Power Lengan & 0,20 & 0,05 & Normal \\
\hline & \multicolumn{4}{c}{ Kelompok Kontrol } & \\
\hline Pretest Power Tungkai & 0,87 & 0,05 & Normal \\
Posttest Power Tungkai & 0,18 & 0,05 & Normal \\
Pretest Power Lengan & 0,20 & 0,05 & Normal \\
Posttest Power Lengan & 0,10 & 0,05 & Normal \\
\hline
\end{tabular}

Tabel 6. Uji Homogenitas

\begin{tabular}{ccccc}
\hline Kelompok & df1 & df2 & Sig. & Keterangan \\
\hline Pretest Power Tungkai & 1 & 20 & 0,95 & Homogen \\
Posttest Power Tungkai & 1 & 20 & 0,18 & Homogen \\
Pretest Power Lengan & 1 & 20 & 0,12 & Homogen \\
Posttest Power Lengan & 1 & 20 & 0,45 & Homogen \\
\hline
\end{tabular}

Tabel 7. Uji t Kelompok Eksperimen

\begin{tabular}{|c|c|c|c|c|c|c|}
\hline \multirow{2}{*}{\multicolumn{2}{|c|}{ Kelompok }} & \multirow{2}{*}{$\bar{X}$} & \multicolumn{4}{|c|}{ t-test for Equality of means } \\
\hline & & & $t_{\text {hitung }}$ & $\mathbf{t}_{\text {tabel }}$ & Sig. & $\%$ \\
\hline $\begin{array}{l}\text { Power } \\
\text { Tungkai }\end{array}$ & $\begin{array}{l}\text { Pre-test } \\
\text { Post-test }\end{array}$ & $\begin{array}{l}50,36 \\
70,00\end{array}$ & 12,61 & 2,228 & 0,00 & $28,05 \%$ \\
\hline $\begin{array}{l}\text { Power } \\
\text { Lengan }\end{array}$ & $\begin{array}{l}\text { Pre-test } \\
\text { Post-test }\end{array}$ & $\begin{array}{l}4,3 \\
5,0\end{array}$ & 5,90 & 2,228 & 0,00 & $14 \%$ \\
\hline
\end{tabular}

Tabel 8. Uji t Kelompok Kontrol

\begin{tabular}{|c|c|c|c|c|c|c|}
\hline \multirow{2}{*}{\multicolumn{2}{|c|}{ Kelompok }} & \multirow[t]{2}{*}{$\bar{X}$} & \multicolumn{4}{|c|}{ t-test for Equality of means } \\
\hline & & & $\mathbf{t}_{\text {hitung }}$ & $t_{\text {tabel }}$ & Sig. & $\%$ \\
\hline Power & Pre-test & 49,36 & 1.28 & 2.228 & & $2,1 \%$ \\
\hline Tungkai & Post-test & 50,45 & 1,28 & 2,228 & 0,22 & $2,1 \%$ \\
\hline Power & Pre-test & 4,06 & 181 & 2228 & 0.10 & $4.2 \%$ \\
\hline Lengan & Post-test & 4,24 & & & & \\
\hline
\end{tabular}

Hipotesis pertama dalam penelitian ini adalah adakah pengaruh latihan complex training terhadap power tungkai. Dari hasil pengujian statistik diketahui bahwa pada kelompok eksperimen memiliki nilai $t_{\text {hitung }}(12,61)>t_{\text {tabel }}(2,22)$ dengan signifikansi 0,00 . Sedangkan pada kelompok kontrol nilai $t_{\text {hitung }}(1,28)<t_{\text {tabel }}(2,22)$ dengan signifikasi 0,22. Berdasarkan hasil uji statistik tersebut menyatakan bahwa ada pengaruh signifikan latihan complex training terhadap power otot tungkai, dengan peningkatan sebesar $28,05 \%$.

Pada hipotesis kedua dalam penelitian ini adalah untuk menguji adalah pengaruh latihan complex training terhadap power lengan. Berdasarkan pengujian statistik diketahui bahwa pada kelompok eksperimen memiliki nilai $t_{\text {hitung }}(5,90)>t_{\text {tabel }}(2,22)$ dengan signifikasi 0,00 . Pada kelompok kontrol memiliki nilai $t_{\text {hitung }}(1,81)<t_{\text {tabel }}(2,22)$ dengan signifikansi 0,10 . Berdasarkan hasil uji statistik tersebut menyatakan bahwa ada pengaruh yang signifikan latihan complex training terhadap peningkatan power lengan, dengan peningkatan hasil latihan sebesar $14 \%$. 
Temuan utama dari penelitian ini adalah terjadi peningkatan power otot tungkai dan power otot lengan yang signifikan diakibatkan oleh berlatih dengan menggunakan metode complex training. Hal ini terlihat dari terdapat perbedaan rerata pada pretest dan postest baik pada kelompok eksperimen maupun kelompok kontrol untuk power otot tungkai dan lengan.

Pada power otot tungkai hasil yang didapatkan adalah pada kelompok eksperimen terjadi perbedaan rerata yaitu 50,36 menjadi 70,00, sedangkan pada kelompok kontrol juga terjadi perbedaan yaitu 49,36 menjadi 50,45. Lebih lanjut, diketahui peningkatan terjadi yaitu besar 28,08\% pada kelompok eksperimen dan 2,1\%. Pada power otot lengan hasil yang didapatkan adalah pada kelompok eksperimen memiliki rerata 4,3 menjadi 5,0, sedangkan pada kelompok kontrol 4,06 menjadi 4,24. Analisis lebih lanjut diketahui terjadi peningkatan sebesar $14 \%$ pada kelompok eksperimen dan 4,2\%. Temuan ini menunjukan kualitas desain program latihan yang implementasinya dilakukan selama 12 minggu berlatih.

Peningkatan yang terjadi pada penelitian ini berupa peningkatan power otot tungkai dan power otot lengan. Menurut Dawes dan Roozen (2012) power mewakili tingkat pekerjaan dan merupakan konsep yang sangat penting dalam suatu keterampilan. Dalam permainan bola voli, power otot merupakan esensi. Dengan memiliki power yang baik memungkinkan seorang atlet dapat mengubah arah dalam bergerak, melompat atau meloncat hingga memukul dengan keras. Sehingga, untuk melakukan teknik menyerang maupun bertahan power otot sangat dibutuhkan. Dengan demikian keberhasilan suatu keterampilan dalam permainan bola voli membutuhkan power yang baik.

Program latihan dalam penelitian ini dirancang untuk menigkatkan power otot tungkai dan power otot lengan menggunakan metode complex training. Complex training merupakan metode latihan yang menggabungkan latihan beban dan pliometrik dalam satu sesi latihan. Lebih spesifik, metode ini merupakan latihan beban yang diikuti oleh latihan pliometrik yang serupa secara mekanis dengan latihan beban tersebut (May, Cipriani, \& Lorenz, 2010).

Metode complex training dapat digunakan untuk tubuh bagian atas maupun bagian bawah. Dua unsur yang terkandung dalam complex training memiliki perannya masingmasing dalam mengembangkan kemampuan atletis atlet. Lebih lanjut May, Cipriani, dan Lorenz (2010) mengemukakan bahwa unsur pliometrik menyebabkan kontraksi otot yang bekerja dengan cepat yang meningkatkan kecepatan peregangan dan kekuatan yang dihasilkan. Sedangkan unsur latihan beban digunakan untuk meningkatkan produksi kekuatan pada akhir suatu rentang gerak. Beban yang digunakan dalam penelitian ini berupa barbell, beban tubuh dan medice ball.

Beberapa faktor mungkin yang berkontribusi pada peningkatan yang terjadi pada penelitian ini yaitu semakin meningkatnya power otot akibat dari latihan maupun semakin meningkatnya level koordinasi otot. Selain itu faktor lain yang mungkin berkontribusi adalah terkait dengan peningkatan power dalam penelitian ini adalah dari segi keterampilan bola.

Post-activation potentiation (PAP) merupakan peningkatan daya otot setelah latihan intensitas tinggi (Blazevich \& Babault, 2019), merupakan faktor yang berkontribusi terhadap status keterlatihan atlet, pengalaman latihan beban dan tingkat kekuatan (Lim \& Barley, 2016). Menurut Lorenz (2011) latihan kekuatan sebelum latihan plyometrics menyebabkan peningkatan eksitasi sinaptik dalam sumsum tulang belakang, yang pada gilirannya menghasilkan peningkatan potensi post-sinaptik dan selanjutnya peningkatan 
kapasitas pembangkit kekuatan kelompok otot yang terlibat. Indikator PAP yang paling umum adalah peningkatan kontraksi isometric yang terus-menerus.

Meskipun mengalami peningkatan, hal lain yang harus menjadi perhatian dalam latihan ini adalah waktu istirahat. Waktu istirahat akan sangat menentukan sejauh mana peningkatan akan dicapai. Dalam metode complex training, terdapat istirahat yang disebut Intra Complex Rest Interval (ICRI). Intra Complex Rest Interval (ICRI) merupakan kunci untuk mendapatkan hasil yang optimal.

Faktor hormonal juga dapat menjadi faktor yang menyebabkan peningkatan hasil dari latihan complex training. Seperti diketahui bahwa hormone saliva membantu dalam meningkatkan kekuatan (power) berdasarkan respon dari program latihan (Shariat, Kargarfard, Danaee, \& Tamrin, 2015). Lloyd dan Oliver (2012) mengungkap bahwa pada usia remaja komponen fisik akan meningkat pesat karena peningkatan lingkungan internal androgenik.

Beberapa hasil penelitian terdahulu yang mendukung bahwa complex training dapat meningkatkan power otot tubuh antara lain, hasil penelitian yang dilakukan oleh Smith, Lyons, dan Hannon (2014), yang menemukan bahwa complex training berpotensi meningkatkan kekuatan tubuh bagian bawah. Selanjutnya dalam temuan Talpey, Young, dan Saunders (2016) menunjukan bahwa kelompok complex training memiliki peningkatan yang signifikan lebih besar dari kelompok latihan konvensional. Sedangkan pada kecepatan tidak mengalami peningkatan yang signifikan. Sedangkan temuan Thompson, Berning, Harris, Kent, dan Debeliso (2017) menunjukan bahwa complex training dapat meningkatkan kekuatan dan power atlet putra. Hal ini dapat menjadi dasar bahwa latihan menggunakan complex training dapat menjadi pilihan dalam meningkatkan power otot tubuh bagian bawah dan bagian atas pada atlet remaja bola voli.

\section{KESIMPULAN}

Berdasarkan hasil penelitian dan analisis data yang dilakukan, maka memperoleh kesimpulan bahwa terdapat pengaruh yang signifikan latihan mengunakan metode complex training terhadap peningkatan power pada tubuh bagian bawah dan atas bagi atlet bola voli tingkat remaja. Oleh karena itu, metode ini sangat cocok untuk digunakan bagi atlet bola voli tingkat remaja yang telah memiliki pengalaman latihan beban dalam meningkatkan power otot bagi atlet bola voli tingkat remaja. Dalam penelitian ini, yang menjadi keterbatasan penelitian antara lain jumlah sampel yang tidak terlalu besar sehingga hasil penelitian tidak dapat digeneralisasikan. Sedangkan rekomendasi bagi peneliti berikutnya adalah perlu menambah jumlah sampel yang digunakan.

\section{DAFTAR PUSTAKA}

Ali, K., M, E. H., Verma, S., Ahmad, I., Singla, D., \& Jha, P. (2017). Complex training: An Update. Journal of Athletic Enhancement, 6(3), 1-5. https://doi.org/10.4172/2324-9080.1000261.

Blazevich, A. J., \& Babault, N. (2019). Post-activation Potentiation Versus Postactivation Performance Enhancement in Humans: Historical Perspective, Underlying Mechanisms, and Current Issues. Frontiers in Physiology, 10(November). https://doi.org/10.3389/fphys.2019.01359. 
Carter, J., \& Greenwood, M. (2014). Complex training reexamined: Review and recommendations to improve strength and power. Strength and Conditioning Journal, 36(2), 11-19. https://doi.org/10.1519/SSC.0000000000000036.

Dawes, J., \& Roozen, M. (2012). Developing Agility and Quickness (NSCA Sport Performance), 2nd Edition. Champaign: Human Kinetics.

De Salles, B. F., Simão, R., Miranda, F., Da Silva Novaes, J., Lemos, A., \& Willardson, J. M. (2009). Rest interval between sets in strength training. Sports Medicine, 39(9), 766-777. https://doi.org/10.2165/11315230-000000000-00000.

Faigenbaum, A. D., \& Myer, G. D. (2010). Resistance training among young athletes: Safety, efficacy and injury prevention effects. British Journal of Sports Medicine, 44(1), 56-63. https://doi.org/10.1136/bjsm.2009.068098.

Fukuda, D. H. (2019). Assessments for Sport and Athletic Performance. Champaign: Human Kinetics.

Lim, J. J. H., \& Barley, C. I. (2016). Complex Training for Power Development: Practical Applications for Program Design. Strength and Conditioning Journal, 38(6), 33-43. 10.1519/SSC.0000000000000265.

Lloyd, R. S., \& Oliver, J. L. (2012). The youth physical development model: A new approach to long-term athletic development. Strength and Conditioning Journal, 34(3), 61-72. https://doi.org/10.1519/SSC.0b013e31825760ea

Lorenz, D. (2011). Clinical Commentary. The International Journal of Sports Physical Therapy, 6(3), 72-87.

Lorenz, D. (2011). Postactivation potentiation: An introduction. International Journal of Sports Physical Therapy, 6(3), 234-240.

Macaluso, T. D. (2010). Periodization and complex training in a high school summer program. Strength and Conditioning Journal, 32(6), 95-98. https://doi.org/10.1519/SSC.0b013e3181e8e30b

Mansur, L. K., Irianto, J. P., \& Mansur, M. (2018). Pengaruh latihan squat menggunakan free weight dan gym machine terhadap kekuatan, power, dan hypertrophy otot. Jurnal Keolahragaan, 6(2), 150-161. https://doi.org/10.21831/jk.v6i2.16516

May, C. A., Cipriani, D., \& Lorenz, K. A. (2010). Power development through complex training for the division I collegiate athlete. Strength and Conditioning Journal, 32(4), 30-43. https://doi.org/10.1519/SSC.0b013e3181dd8f47

Mohamed, G. A. (2011). Effects of Complex Trajning on Certain Physical Variables and Performance Level of Landing in Floor Exercise. Ovidius University Annals, Series Physical Education \& Sport/Science, Movement \& Health, 11(2), 171-175. 
Reynaud, C. (2011). Coaching Volleyball Technical and Tactical Skills. Champaign: Human Kinetics.

Shariat, A., Kargarfard, M., Danaee, M., \& Tamrin, S. B. M. (2015). Intensive resistance exercise and circadian salivary testosterone concentrations among young male recreational lifters. Journal of Strength and Conditioning Research, 29(1), 151-158. https://doi.org/10.1519/JSC.0000000000000632

Smith, C. E., Lyons, B., \& Hannon, J. C. (2014). A pilot study involving the effect of two different complex training protocols on lower body power. Human Movement, 15(3), 141-146. https://doi.org/10.1515/humo-2015-0003

Talpey, S. W., Young, W. B., \& Saunders, N. (2016). Is nine weeks of complex training effective for improving lower body strength, explosive muscle function, sprint and jumping performance?. International Journal of Sports Science and Coaching, 11(5), 736-745. https://doi.org/10.1177/1747954116667112

Thompson, T., Berning, J., Harris, C., Kent, J., \& Debeliso, M. (2017). The Effects of Complex Training in Male High School Athletes on the Back Squat and Vertical Jump. International Journal of Sport Science, 7(2), 50-55. https://doi.org/10.5923/j.sports.20170702.05 